\title{
Polyubiquitin-Proteasomal Degradation of Leucine-Rich Repeat Kinase 2 Wildtype and G2019S
}

\author{
Sangwook Park ${ }^{\dagger, *}$ \\ Department of Biomedical Laboratory Science, College of Health and Medical Science, \\ Sangii University, Wonju 26339, Korea
}

\begin{abstract}
Parkinson disease (PD) is becoming one of the most neurodegenerative disorder worldwide. The deposited aggregates have been connected in the pathophysiology of PD, which are degraded either by ubiquitin-proteasomal system (UPS) or autophagy-lysosomal pathway (ALP). Leucin-rich repeat kinase 2 (LRRK2), one of the neurodegenerative proteins of PD is also stringently controlled by both UPS and ALP degradation as well. However, the polyubiquitination pattern of LRRK2 aggregates is largely unknown. Here, we found that K63-linked polyubiquitinations of G2019S mutant, most familial variant for PD, is highly enhanced compared to those of wild type LRRK2 (WT). In addition, in the presence of overexpressed p62/SQSTM-1, ubiquitination of LRRK2 WT or D1994A was reduced, whereas G2019S mutant was not diminished significantly. Therefore, we propose that degradation of G2019S via UPS is more involved with K63-linked ubiquitination than K48-linked ubiquitination, and overexpressed p62/SQSTM-1 does not enhance degradative effect on G2019S variant.
\end{abstract}

Key Words: Leucin-rich repeat kinase 2, Parkinson disease, P62/SQSTM-1, Ubiquitin-Proteasomal system

파킨슨병(Parkinson disease, PD)은 병리학적으로 중뇌의 흑색질(substantia nigra) 부위에 도파민성 뉴런이 소실되 어 일어나는 질병으로 잘 알려져 있으며 $\alpha$-synuclein 응집 (aggregate)을 나타내는 세포성 봉입체(inclusion)인 Lewy body를 형성한다. 물론 임상적으로 파키슨병 환자가 가지 고 있는 운동성 증상들-손떨림, 근육의 경직성, 느린행동 등과 비운동성 증상-변비, 후각상실, 우울증, 수면장애 등 이 비도파민성 신경세포와 연관되어 있다(Simon et al., 2020). PD를 유발시키는 유전자는 $\alpha$-synuclein을 형성하는 SNCA (Polymeropoulos et al., 1997), PARKIN (Valente et al., 2004)과 PINK1 (Shin et al., 2011) 등은 mitophagy를 유도 하고, 전사인자인 NRF2를 통해 항산화효과를 유도하는 $D J-1$ (Bonifati et al., 2003), Gaucher's disease와 연관된 $G B A$ ( $\beta$-glucocerebrosidase) 유전자(Clark et al., 2005), 그리고 가
족성 $\mathrm{PD}$ 의 $5 \%$, 전체 $\mathrm{PD}$ 환자의 $\sim 2 \%$ 가량을 차지하는 LRRK2 (Alessi and Sammler, 2018) 등이 있다. Leucine-rich repeat kinase 2 (LRRK2)는 GTPase와 kinase 도메인 등을 함 유하는 2,527 개 아미노산으로 구성된 $286 \mathrm{kDa}$ 의 분자량을 지닌 매우 큰 단백질이다(Cookson, 2010). LRRK2 유전자의 다양한 돌연변이들이 파킨슨병의 원인으로 알려져 있는 데 G2019S 변이가 가장 흔히 발견되며 이 돌연변이로 인 해 kinase 활성을 증가시키는 것으로 알려져 있다(Nguyen et al., 2020). 2013년 Orenstein 등은 chaperone-mediated autophagy (CMA)를 매개로 LRRK2가 lysosome에서 분해 된다고 밝혔다(Orenstein, et al., 2013). 최근에 Park 등은 p62/SQSTM-1을 매개로 LRRK2가 autophagy-lysosomal pathway (ALP)를 통해 분해된다고 보고하는 등 LRRK2 단백 질 사멸 기전에 대한 다양한 결과가 보고되었다(Ho et al.,

Received: July 19, 2021 / Revised: August 6, 2021 / Accepted: August 10, 2021

*Professor.

${ }^{\dagger}$ Corresponding author: Sangwook Park. Department of Biomedical Laboratory Science, College of Health and Medical Science, Sangji University, 83 Sangiidae-gil, Wonju-si, Gangwon-do 26339, Korea.

Tel: +82-33-738-7682, Fax:+82-33-738-7652, e-mail: spark367@sangji.ac.kr

(C)The Korean Society for Biomedical Laboratory Sciences. All rights reserved.

(2) This is an Open Access article distributed under the terms of the Creative Commons Attribution Non-Commercial License (http://creativecommons.org/licenses/by-nc/3.0/) which permits unrestricted non-commercial use, distribution, and reproduction in any medium, provided the original work is properly cited. 
2020; Park et al., 2016). 진핵세포에서 정상적인 단백질 소 멸은 ubiquitin-proteasome system (UPS)와 ALP를 통해 세포 내 단백질 분해가 이루어진다. 최근 연구에 의하면 $\mathrm{p} 62$, NBR1 (neighbor of BRCA1 gene 1) (Kirkin et al., 2009), NDP52 (nuclear dot protein 52) (Thurston et al., 2009), OPTN (optineurin) (Liu et al., 2014) 등이 선택적 자가포식(autophagy)을 통해 단백질을 소멸시키는 역할을 한다. 본 연 구에서는 LRRK2가 UPS를 통해 단백질 소멸을 관찰하였 다. 특히, G2019S 돌연변이와 wildtype (LRRK2)간의 ubiquitination 패턴(K48-/K63-linked)의 차이점을 확인하였고 p62의 과발현 시 polyubiquitination의 변화를 관찰하였다. 이를 통해 LRRK2와 G2019S의 단백질 사멸과정을 이해하 는 데 도움을 줄 수 있을 것으로 기대한다. LRRK2 wildtype과 LRRK2 G2019S의 polyubiquitination 차이를 확인 하기 위하여 공동면역침강법(Co-immunoprecipitation assay, $\mathrm{Co}-\mathrm{IP})$ 를 이용하였다. Myc-LRRK2와 HA-Ub (K48) 또는 $\mathrm{HA}-\mathrm{Ub}$ (K63)를 HEK293T 세포에 공동 과발현 시킨 후 anti-Myc antibody를 이용하여 pull-down 시킨 후 anti-HA antibody로 immunoblot 시켜 polyubiquitination 패턴을 확 인하였다. HEK293T 세포를 배양하기 위해 6-well plate에 DMEM [10\% FBS, Penicillin-Streptomycin (100 U/mL)]을 well당 $0.8 \times 10^{6}$ 개씩 각각 분주하였다. $37^{\circ} \mathrm{C}$ 배양기에 $5 \%$ $\mathrm{CO}_{2}$ 공급 하에 세포를 안정적으로 배양한 후, $70 ~ 80 \%$ 세 포가 자라났을 때 $1.5 \mathrm{~mL}$ tube에 DMEM (serum 미포함)을 $30 \mu \mathrm{L}$ 씩 분주하고 각 tube에 Co-IP에 필요한 총 plasmid 양과 PolyJet (SignaGen Laboratories, USA)을 1:3 비율로 첨가하였다. 미가공된(crude) 단백질인 총세포용해물(total cell lysate)을 회수하기 전 PBS로 1회 세척 후 ice 위에 놓 고 protease inhibitor cocktails (Roche, Germany)를 총용량의 $1 / 10$ 가량 첨가한 RIPA cell lysis buffer $(150 \mathrm{mM} \mathrm{NaCl}, 1 \%$ NP-40, 1\% sodium deoxycholate, $0.1 \%$ SDS, 2 mM EDTA, $50 \mathrm{mM}$ Tris- $\mathrm{HCl}, \mathrm{pH}$ 7.6)를 well당 $200 \mu \mathrm{L}$ 분주한 뒤 cell lifter (SPL, Korea)를 이용하여 $1.5 \mathrm{~mL}$ tube에 담았다. 회수 한 세포용해물은 원심분리 $\left(10,000 \mathrm{~g}, 4^{\circ} \mathrm{C}, 5 \mathrm{~min}\right)$ 하여 상층 액을 새 tube에 분리한 후 다음 실험에 사용하기 전까지 ice에 꽂아 두었다. 총세포용해물 상층액 $200 \mu \mathrm{L}$ 와 Protein G Sepharose 4 Fast Flow (GE Helthcare, USA) $20 \mu \mathrm{L}$ 를 $4{ }^{\circ} \mathrm{C}$ 에서 미리 제거시켰다(pre-clearing). 원심분리하여 상층액 을 분리한 후 1차 항체 $1 \mu \mathrm{L} \mathrm{Myc} \mathrm{9E10} \mathrm{( \# M5546)} \mathrm{(Sigma-}$ Aldrich, USA)를 첨가하여 rotary mixer에서 회전시켜 반응 시킨 후 $\left(4^{\circ} \mathrm{C}, 1 \mathrm{hr}\right)$, Protein $\mathrm{G}$ Sepharose bead $20 \mu \mathrm{L}$ 를 $4{ }^{\circ} \mathrm{C}$ 에 서 약 2 시간 동안 면역침강(precipitation) 시켰다. 반응 후
원심분리하여 면역침강물을 회수하여 lysis buffer로 3회 이상 세척 후 $5 \mathrm{X}$ sample buffer $(60 \mathrm{mM}$ Tris- $\mathrm{HCl} \mathrm{pH} 6.8$, $25 \%$ glycerol, $2 \%$ SDS, $0.1 \%$ bromophenol blue, $2 \% \beta$ mercaptoethanol) $8 \mu \mathrm{L}$ 와 lysis buffer $32 \mu \mathrm{L}$ 첨가하여 $100^{\circ} \mathrm{C}$ 에 서 5 분간 끓였다. $1000 \mathrm{~g} 1$ 분간 원심분리 후 상층액을 회수 하여 SDS-PAGE 전기영동 후 Immunoblot으로 polyubiquitination된 단백질을 분석하였다. Wildtype (Myc-LRRK2), D1994A (Myc-D1994A, kinase dead variant), G2019S (MycG2019S varinat)와 HA-Ub (K48) 및 HA-Ub (K63)를 HEK293T에 과발현을 유도하였다. 이후, 공동면역침강법(CoImmunoprecipitation assay, Co-IP)을 이용하여 UPS를 통 한 wildtype LRRK2와 mutant 간의 K48- 또는 K63-linked polyubiquitination 확인하였다. Wildtype LRRK2 유비퀴틴 화의 경우 $\mathrm{K} 48 / \mathrm{K} 63$-linked polyubiquitination에 차이를 보 이지는 않았다. 그러나 G2019S mutant의 경우에는 K63linked polyubiquitination $(\mathrm{Ub})$ 이 K48-linked $\mathrm{Ub}$ 보다 많이 일어나는 경향을 보였다 $(P<0.05)$. 인위적으로 LRRK2의 kinase domain 기능을 비활성화시킨 D1994A mutant인 경우 도 K63-linked $\mathrm{Ub}$ 이 대부분 일어나는 경향을 띄었다(Fig. $1 \mathrm{~A}, \mathrm{~B})$. 한편, p62/SQSTM-1을 과발현(FLAG-p62) 시킨 후 wildtype, D1994A, G2019S의 Ub과 endogenous p62 상태의 LRRK2 (wildtype, D1994A, G2019S)간의 Ub을 확인하였다. Wildtype과 D1994A는 과발현된 FLAG-p62 조건에서는 예 상했듯이 autophage lysosomal pathway (ALP)로 단백질 분 해경향을 보여주었다. 상대적으로 적은 p62를 지속적으 로 발현하는 endogenous p62에서는 UPS 경로의 역할이 높은 것으로 나타났다 $(P<0.05)$. 그런데, $\mathrm{G} 2019 \mathrm{~S}$ 인 경우에 는 p62의 영향을 상대적으로 적게 받았음을 알 수 있다 (Fig. 1C, D). G2019S variant인 경우에는 과발현된 p62 상태 에서도 상대적으로 wildtype과 비교했을 때, ALP 경로의 유비퀴틴화를 보여주었다. Kinase 도메인을 비활성화시킨 D1994A mutant의 경우, UPS를 통한 LRRK2의 K63-linked $\mathrm{Ub}$ 이 G2019S보다 높았다는 점은 흥미롭다. G2019S의 경 우 kinase 활성이 증가했는 데 kinase를 없애면 더욱 UPS 경로의 단백질 분해가 증가하는 바, 아마도 kinase의 활성 도가 UPS 단백질 사멸에도 영향을 줄 수 있을 것으로 본 다. 본 실험은 LRRK2가 UPS 경로를 통해 단백질이 소실 될 때 K48-linked $\mathrm{Ub}$ 또는 K63-linked $\mathrm{Ub}$ 경로인지 확인 하였다. 진핵세포 내 단백질의 소멸은 대표적인 경로인 UPS와 ALP 통해 조절된다. ALP의 첫 단계인 autophagy 는 mitophagy처럼 phagophore를 형성하여 autophagosome 을 형성한 후 lysosome과 융합하여 autolysosome을 형성하 
(A)

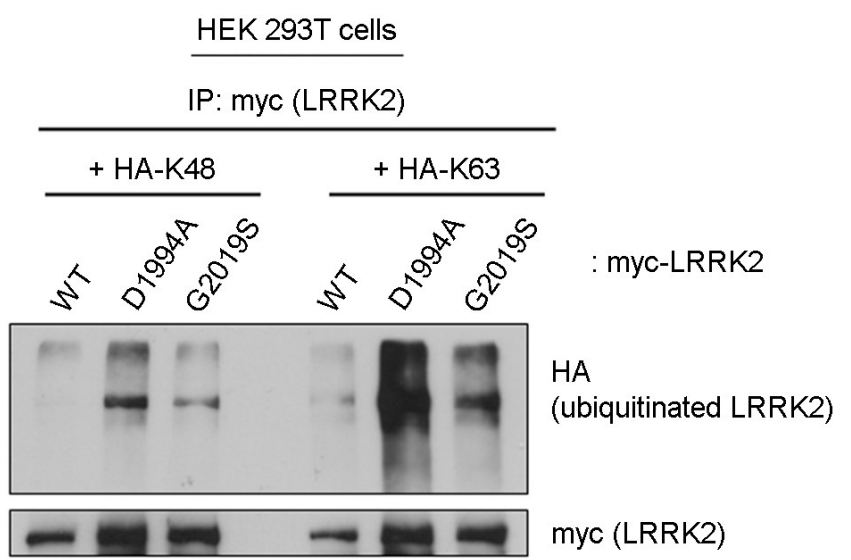

C

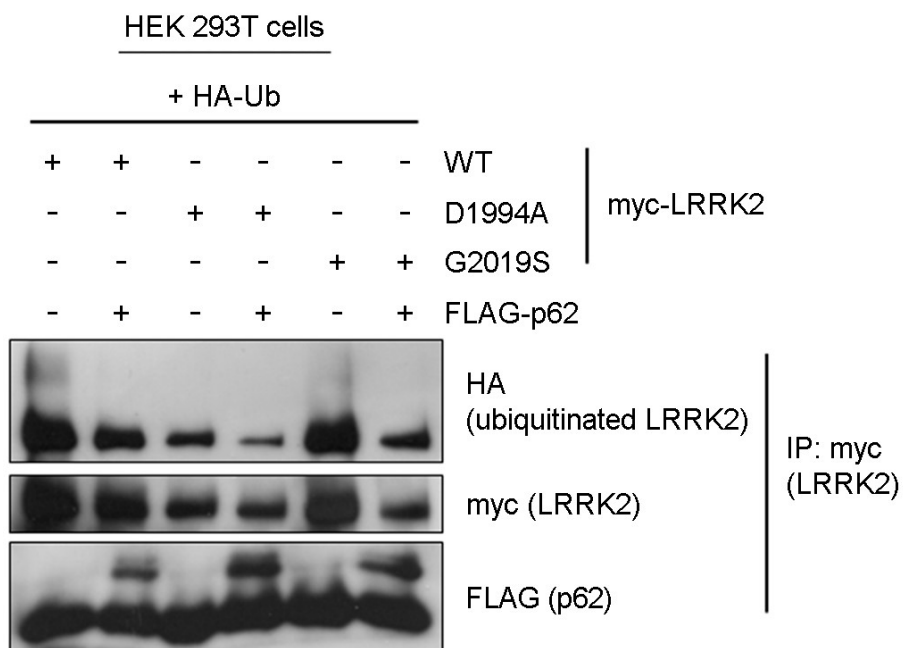

B

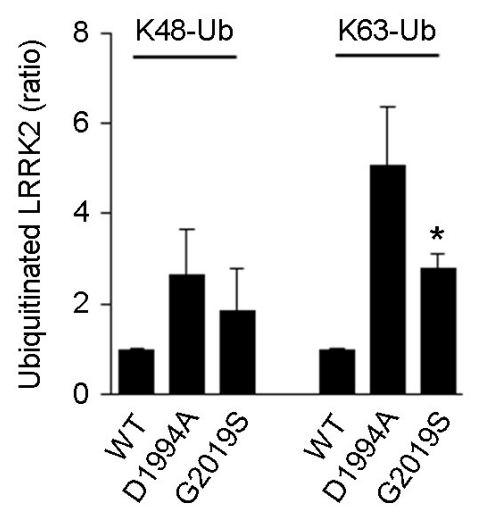

(D)

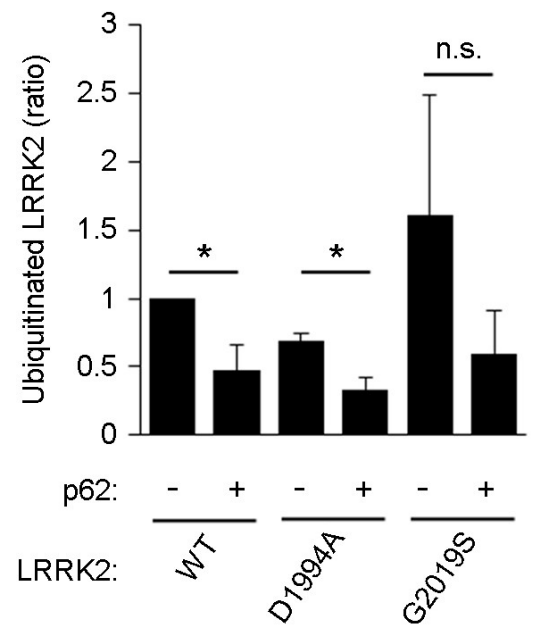

Fig. 1. The ubiquitination of LRRK2 wildtype and G2019S mutant are differentially regulated by p62/SQSTM1. (A) K63-linked ubiquitination is increased in LRRK2 G2019S mutant compared with LRRK2 WT. Myc-tagged LRRK2 WT or G2019S was co-transfected with HA-tagged K48 Ub or K63 Ub in HEK 293T cells. The ubiquitination of LRRK2 was detected using anti-HA antibody following immunoprecipitation with anti-myc antibody. (B) Quantification graph from panel A. The data represent means of ubiquitinated LRRK2 \pm SEM (K48-Ub WT, 1.00 \pm 0.00 ; D1994A, 2.67 \pm 0.98 ; G2019S, 1.85 \pm 0.93 ; K63-Ub WT, $1.00 \pm 0.00$; D1994A, 5.07 \pm 1.30 ; G2019S, $2.81 \pm$ $0.29 ; \mathrm{n}=3 ;{ }^{*} P<0.05$, paired $t$-test). (C) The overexpression of $\mathrm{p} 62$ reduces the ubiquitination of LRRK2 WT or D1994A, whereas does not have a significant effect on LRRK2 G2019S mutant. HEK 293T cells were co-transfected with HA-Ub and myc-LRRK2 WT or G2019S, and then the ubiquitination of LRRK2 was detected as in panel A. (D) The summary quantification are shown as means \pm SEM (WT, 1.00 \pm 0.00 ; WT with p62, $0.48 \pm 0.18$; D1994A, 0.69 \pm 0.06 ; D1994A with p62, 0.33 \pm 0.09 ; G2019S, 1.61 \pm 0.87 ; G2019S with p62, 0.60 \pm 0.32 ; $\mathrm{n}=3 ; * P<0.05$, n.s., $P>0.05$, paired $t$-test).

여 단백질을 해체하는 형태의 macroautophagy와 autophagy 의 과정없이 lysosome/late endosome이 직접 내재화하여 분해하는 microautophagy, 그리고 Heat shock cognate 70 (Hsc70)과 cochaperones이 분해할 단백질을 lysosome의 Lamp-2A의 활성을 유도함으로써 내재화하여 해체하는 방식인 chaperone-mediated autophagy (CMA)으로 나눌 수 있다(Mizushima and Komatsu, 2011). 그 외 ER-associated proteasomal degradation (ERAD) 방식의 단백질 해체 경로도 있다(Hampton, 2002). LRRK2는 primary neurons에서 proteosome과 lysosome에서 단백질 해체가 이루어짐을 확인 하였고 특히 p62와 결합하여 선택적 자가포식(autophagy) 를 통해 LRRK2가 소멸된다는 사실은 밝혀졌다(Park et al., 2016). 그러나 Orenstein 등은 CMA를 통해서만 LRRK2 가 소멸된다고 보고하였다. 본 연구결과는 LRRK2가 UPS 
를 통한 단백질 소멸을 직접 확인하였으며 이는 ALP 경 로뿐만 아니라 UPS 경로도 단백질 소멸과정에 중요함을 확인할 수 있었다. 향후, UPS를 통한 LRRK2의 단백질 소 실과정에 관여하는 단백질과 상호관계를 밝혀 낸다면 PD 병인성을 이해하는 데 도움이 될 것으로 기대한다.

\section{ACKNOWLEDGEMENT}

This study was supported by the Basic Science Research Program through the National Research Foundation of Korea (NRF) grant (http://ernd.nrf.re.kr) to S.P (NRF-2017R1D1A3B03029902), which was funded by the Ministry of Education

\section{CONFLICT OF INTEREST}

The author declares no conflict of interest.

\section{REFERENCES}

Alessi DR, Sammler E. LRRK2 kinase in Parkinson's disease. Science. 2018. 360: 36-37.

Bonifati V, Rizzu P, van Baren MJ, Schaap O, Breedveld GJ, Krieger E, Dekker MC, Squitieri F, Ibanez P, Joosse M, van Dongen JW, Vanacore N, van Swieten JC, Brice A, Meco G, van Duijn CM, Oostra BA, Heutink P. Mutations in the DJ-1 gene associated with autosomal recessive early-onset parkinsonism. Science. 2003. 299: 256-259.

Clark LN, Nicolai A, Afridi S, Harris J, Mejia-Santana H, Strug L, Cote LJ, Louis ED, Andrews H, Waters C, Ford B, Frucht S, Fahn S, Mayeux R, Ottman R, Marder K. Pilot association study of the beta-glucocerebrosidase N370S allele and Parkinson's disease in subjects of Jewish ethnicity. Mov Disord. 2005. 20: 100-103.

Cookson MR. The role of leucine-rich repeat kinase 2 (LRRK2) in Parkinson's disease. Nat Rev Neurosci. 2010. 11: 791-797.

Hampton RY. ER-associated degradation in protein quality control and cellular regulation. Curr Opin Cell Biol. 2002. 14: 476-482.

Ho PW, Leung CT, Liu H, Pang SY, Lam CS, Xian J, Li L, Kung MH, Ramsden DB, Ho SL. Age-dependent accumulation of oligomeric SNCA/ $\alpha$-synuclein from impaired degradation in mutant LRRK2 knockin mouse model of Parkinson disease: role for therapeutic activation of chaperone-mediated autophagy (CMA). Autophagy. 2020. 16: 347-370.

Kirkin V, Lamark T, Sou YS, Bjørkøy G, Nunn JL, Bruun JA,
Shvets E, McEwan DG, Clausen TH, Wild P, Bilusic I, Theurillat JP, Øvervatn A, Ishii T, Elazar Z, Komatsu M, Dikic I, Johansen T. A role for NBR1 in autophagosomal degradation of ubiquitinated substrates. Mol Cell. 2009. 33: 505-516.

Liu Z, Chen P, Gao H, Gu Y, Yang J, Peng H, Xu X, Wang H, Yang M, Liu X, Fan L, Chen S, Zhou J, Sun Y, Ruan K, Cheng S, Komatsu M, White E, Li L, Ji H, Finley D, Hu R. Ubiquitylation of autophagy receptor Optineurin by HACE1 activates selective autophagy for tumor suppression. Cancer Cell. 2014. 26: 106-120.

Mizushima N, Komatsu M. Autophagy: renovation of cells and tissues. Cell. 2011. 147: 728-741.

Nguyen APT, Tsika E, Kelly K, Levine N, Chen X, West AB, Boularand S, Barneoud P, Moore DJ. Dopaminergic neurodegeneration induced by Parkinson's disease-linked G2019S LRRK2 is dependent on kinase and GTPase activity. Proc Natl Acad Sci U S A. 2020. 21; 117: 17296-17307.

Orenstein SJ, Kuo SH, Tasset I, Arias E, Koga H, FernandezCarasa I, Cortes E, Honig LS, Dauer W, Consiglio A, Raya A, Sulzer D, Cuervo AM. Interplay of LRRK2 with chaperonemediated autophagy. Nat Neurosci. 2013. 16: 394-406.

Park S, Han S, Choi I, Kim B, Park SP, Joe EH, Suh YH. Interplay between Leucine-Rich Repeat Kinase 2 (LRRK2) and p62/SQSTM-1 in Selective Autophagy. PLoS One. 2016 11: $\mathrm{e} 0163029$.

Polymerooulos MH, Lavedan C, Leroy E, Ide SE, Dehejia A, Dutra A, Pike B, Root H, Rubenstein J, Boyer R, Stenroos ES, Chandrasekharappa S, Athanassiadou A, Papapetropoulos T, Johnson WG Lazzarini AM, Duvoisin RC, Di Iorio G, Golbe LI, Nussbaum RL. Mutation in the alpha-synuclein gene identified in families with Parkinson's disease. Science. 1997. 276: 2045-2047.

Shin JH, Ko HS, Kang H, Lee Y, Lee YI, Pletinkova O, Troconso JC, Dawson VL, Dawson TM. PARIS (ZNF746) repression of PGC-1 $\alpha$ contributes to neurodegeneration in Parkinson's disease. Cell. 2011. 144: 689-702.

Simon DK, Tanner CM, Brundin P. Parkinson Disease Epidemiology, Pathology, Genetics, and Pathophysiology. Clin Geriatr Med. 2020. 36: 1-12

Thurston TL, Ryzhakov G, Bloor S, von Muhlinen N, Randow F. The TBK1 adaptor and autophagy receptor NDP52 restricts the proliferation of ubiquitin-coated bacteria. Nat Immunol. 2009. 10: 1215-1221.

Valente EM, Abou-Sleiman PM, Caputo V, Muqit MM, Harvey K, 
Gispert S, Ali Z, Del Turco D, Bentivoglio AR, Healy DG, Albanese A, Nussbaum R, González-Maldonado R, Deller T, Salvi S, Cortelli P, Gilks WP, Latchman DS, Harvey RJ, Dallapiccola B, Auburger G, Wood NW. Hereditary early-onset Parkinson's disease caused by mutations in PINK1. Science. 2004. 304: 1158-1160.
https://doi.org/10.15616/BSL.2021.27.3.182

Cite this article as: Park S. Polyubiquitin-Proteasomal Degradation of Leucine-Rich Repeat Kinase 2 Wildtype and G2019S. Biomedical Science Letters. 2021. 27: 182-186. 